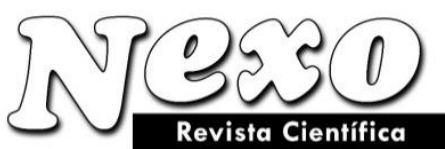

Vol. 34, No. 02, pp. 1039-1048/Junio 2021

\title{
On direct determination of shear force taken up by concrete in oblique cross- sections of reinforced concrete structures
}

\section{Sobre la determinación directa de la fuerza transversal, tomada del concreto en secciones cruzadas oblicuas de estructuras de concreo reforzadas}

\author{
Aleksei N. Morozov \\ Research Institute of Construction, Estonian State Committee, Tallin, Estonia \\ aleksei.morozofff@gmail.com
}

(recibido/received: 25-enero-2021; aceptado/accepted: 15-mayo-2021)

\begin{abstract}
A method has been presented for the direct determination of shear force in oblique cross-sections of reinforced concrete structures using a classic formula $\mathrm{Q}=\mathrm{bz} \tau$, when the main problems of determining the shear force in oblique cross-sections are related to finding cleaving stresses in concrete and the shape of a stress-block of normal stresses in the design section, with no principles of practical division between the forms of failure in oblique sections due to concrete compression or shear. This work incorporates a criterion for dividing the forms of failure due to concrete compression or shear, based on the assumed shape of a compression stress-block with a segment cut away in a normal section, passing through the top of an inclined crack. The height of the compressed area in this normal section is defined from simultaneous solution of the equations of equilibrium in the moments in normal and oblique sections, from testing the experimental beams made of concrete and gas-concrete. This work deals with seeking the approaches for solving the above-mentioned problems in practice. The data of testing beams from gasconcrete and heavy-weight concrete have been used. Strain gauges were used to measure concrete and reinforcement deformities, computer processed thereafter. The studies have been considered on determination of cleaving stresses in oblique sections, further verified according to this method on certain alternative schemes of their application. A practical method for finding the shear force depending on the value of a shear span has been proposed. The work can encourage active discussion of this computation method.
\end{abstract}

Keywords: Direct determination of shear force in oblique cross-sections; Height of a compressed zone; Reinforced concrete elements in oblique sections; Lateral forces; Shear strength

\section{RESUMEN}

El método de la determinación de la fuerza transversal en secciones inclinadas de las estructuras de hormigón armado según la fórmula clásica $\mathrm{Q}=$ bz $\tau$ cuando los principales problemas para determinar la fuerza transversal en las secciones transversales inclinadas están relacionadas con la determinación de los esfuerzos cortantes en el hormigón y la forma de diagrama de tensión normal en la sección transversal de diseño en ausencia de principios de la separación práctica de las formas de fractura de las secciones 
inclinadas transversales de compresión o cizallamiento del hormigón, pero en este estudio basado en la forma adoptada del diagrama de tensiones de compresión con muesca en la sección normal que pasa por el vértice de la fisura inclinada, se da un criterio para separar las formas de fractura de la compresión o el cizallamiento del hormigón, y la altura de la zona comprimida en este sección normal se determina a partir de la solución conjunta de ecuaciones del equilibrio de momentos en las secciones transversales normal y inclinada basadas en los ensayos de vigas experimentales de hormigón y hormigón celular. Este estudio se dedica a la búsqueda de enfoques para soluciones prácticas a los problemas mencionados. Se utilizan datos de ensayos de las vigas de hormigón celular y de hormigón pesado. Deformaciones del hormigón y de la armadura se midieron con medidores de tensión y se procesaron en el ordenador. Estudios sobre la definición de tensiones de cizallamiento en secciones inclinadas con verificación según este método en algunas variantes de su aplicación. Se propone un método práctico para determinar la fuerza transversal en función del tamaño del tramo de cizalladura. Este estudio puede servir de punto de partida para una discusión de este método de cálculo.

Palabras claves: Determinación directa de la fuerza transversal en secciones inclinadas; Altura de la zona de compresión; Elementos de hormigón armado en secciones inclinadas; Fuerzas transversales; Resistencia al cizallamiento.

\section{INTRODUCTION}

Although the known formula,

$$
Q_{b}=b z \tau
$$

for determining the shear force in oblique cross-sections, taken up by concrete, was derived about 100 years ago, it has not found any direct application so far, except for a constraint on its value. Thus, in the existing norms, where and maximum $\mathrm{z}=h_{0}\left(\mathrm{z}=0,9 h_{0}-\tau_{\max }=2,8 R_{b t}\right)$. One of the problems in using formula (1) lies in complexity of finding cleaving stresses $-\tau$. If compression and tensile strength are defined by standard tests, cleaving strength is very difficult to determine due to a complex strain-stress state (SSS) of heterogenous concrete in oblique cross-sections. Hence, behind the experimental data to develop this method for direct determination of the shear force in oblique sections were the results of testing beams made of gas-concrete (Morozov, 2018; 2019a, 2019b) without coarse aggregate, that makes SSS substantially heterogeneous and has low plasticity, what allows more accurate estimates of stresses to be made. The entire practice of experimental studies on this problem indicates that the SSS of the normal section, passing through the top of a critical inclined crack, is highly reflective of the shear force. Previously, the SSS of this section was considered in detail by A.S. Zalesov (1977a, 1977b, 1989) and other his works. The problem of using this section in practice as a design one is constrained by the shape of a stress-block for normal stresses therein. Thus, the simplest triangular shape of a stress-block of normal stresses in concrete is assumed in formula (1) and other works, devoted to the studies of the concrete SSS in oblique cross-sections.

Based on our works (Morozov, 1992, 2015), the closest to experimental data curve of normal stresses in concrete with a cut-out oriented towards the top of an inclined crack (see Figure 1) was assumed. According to this stress-block, there has been derived a formula of normal stresses

$$
\sigma_{b}=\left(\frac{x_{2}}{x_{0}}-1+2 \omega\right) R_{b}
$$


where $x_{2}=x_{0}-x_{1}$. Shear stresses from shear forces are calculated using formula (1) $\tau=\frac{Q}{b z}$ and are obtained from a balance of difference in normal stresses, acting in two parallel sections with distance $d l$ between them. If this condition is considered for a point with the $x_{2}$ ordinate, $\int_{x_{2}}^{x_{0}} b d x_{2} d \sigma_{b}=\tau b d l$ can be written. At $R_{b}=\frac{M}{\omega b x_{0} z}$, taking (2) into account, we obtain $-\sigma=\frac{M}{\omega b x_{0} z}\left(\frac{x_{2}}{x_{0}}-1+2 \omega\right)$, from whence at $Q=\frac{d M}{d l} \tau b d l=\frac{Q_{b} d l}{\omega x_{0} z} \int_{x_{2}}^{x_{0}}\left(\frac{x_{2}}{x_{0}}-1+2 \omega\right) d x_{2}$ and

$$
\tau=\frac{Q_{b}}{b z}\left[\frac{1}{2 \omega}\left(1-\frac{x_{2}^{2}}{x_{0}^{2}}\right)+\left(2-\frac{1}{\omega}\right)\left(1-\frac{x_{2}}{x_{0}}\right)\right]
$$

As per this formula, most failures in oblique cross-sections occur due to concrete compression, and maximum cleaving (shearing, when the SSS is plane) stresses correspond to the neutral axis, i.e. at $x_{2}=$ 0 and the expression in square brackets of formula (3)

$$
m_{0}=\frac{4 \omega-1}{2 \omega}
$$

which is a correction factor for formula (1) and at $\omega=0.5$ formula (4) is transformed into (1). When maximum shearing stresses are at the top of an inclined crack, i.e., at the $x_{2}$ ordinate, it corresponds to failure in oblique sections from concrete shear and the expression in square brackets of formula (3) - $m_{2}$. Thus, the formula of shear force is as follows

$$
Q_{b}=b z m \tau
$$

It follows from the figure

$$
\omega=0.5\left(1+\frac{\sigma_{b}}{R_{b}}-\frac{x_{2}}{x_{0}}\right)
$$

\section{$\mathbf{R b}$}

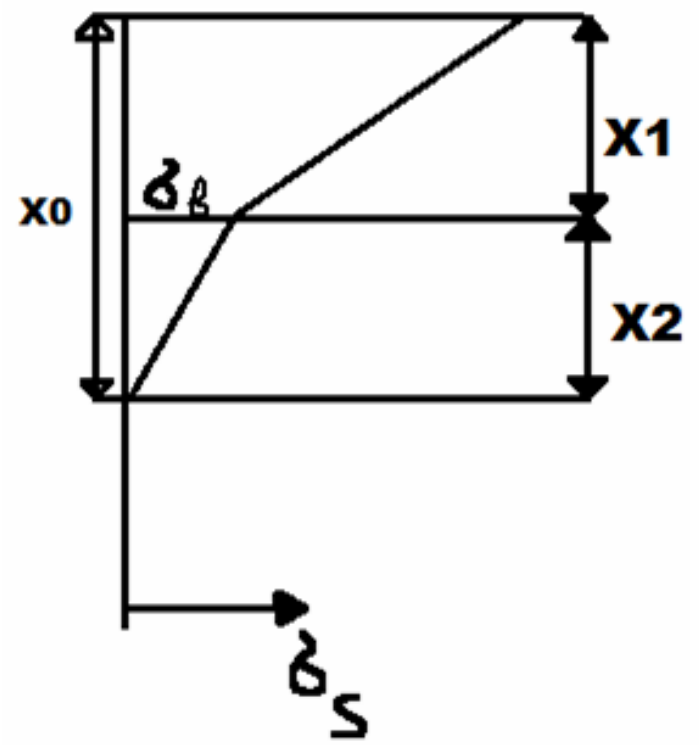

Figure 1. Design diagram of the normal section 
(Morozov, 2019a, 2019b) present a comparison between the experimental values of completeness of a stress-block of normal stresses, computed using this formula, and measured values of this rate in (Morozov, 1985). Due to a low plasticity of gas-concrete, it was not taken into account at the last stages of loading, and measured deformities were accounted for. This comparison demonstrated their satisfactory convergence $\omega / \omega_{\text {act }}=0.94-1.35$, mean $\omega / \omega_{\text {act }}=1.06, \sigma=0.23$, what indicates that the assumed design model is appropriate. When oblique sections are broken up due to concrete compression, an equilibrium equation of moments of longitudinal and lateral forces (in normal and oblique crosssections) can be composed for a design section:

$\xi_{0} \omega b h_{0} R_{b} z=b z m \tau a$ from whence:

$$
\xi_{0}=\frac{X_{0}}{h_{0}}=\frac{\xi_{R}}{\omega}=\frac{m}{\omega} \frac{\tau}{R_{b}} \frac{a}{h_{0}}
$$

what relates this calculation to the relative shear span $-\frac{a}{h_{0}}=\frac{M}{Q h_{0}}$. Equilibrium equation of moments in the design section can be derived for a tensile area as well $-A_{s} \sigma_{s} z=b z m \tau a$, from whence $\mu \sigma_{s}=m \tau \frac{a}{h_{0}}$, what, when substituting into (6), gives $\xi_{0}=\frac{\sigma_{S} \mu}{\omega R_{b}}$ and provides the results absolutely equal to (6), but requires that

$$
\sigma_{s}=\frac{m \tau}{\mu} \frac{a}{h_{0}}
$$

is further determined.

These are the initial conditions for direct calculation of shear force in oblique sections.

The problems of computing the strength of oblique sections of reinforced concrete structures had started to be studied even at the onset of their use. Thus, in 1909 F. Talbot (1909) put forward an idea of transforming a beam with inclined cracks into a restraining system. In 1925, R. Saliger expressed an opinion that the beams with inclined cracks can be considered as bowstring girders. E. Mersch in 1927 proposed a method of so-called truss analogy, considering the compressed zone of concrete as a top chord of a truss, and tensile reinforcement as its bottom chord, compressed concrete of the wall as brace struts. It should be noted that E. Mersch was among the first to derive a classic formula (1). G. G. N. I. Kani (1966) thoroughly explored the effect of the value of a relative shear span in beams on the strength of oblique sections and found that their minimum strength corresponds to $a / h_{0}=2.5$, and when the values of this rate are lower that one and higher than 5-6, the strength of oblique sections becomes equal to the strength of normal sections. Among homeland works, devoted to the problems of strength of oblique crosssections, of note are fundamental works of A. A. Gvozdev (1949) and M. S. Borishanskiy (1946), based on which the norms of calculating strength in oblique cross-sections of reinforced concrete structures were developed. Writings of A. S. Zalesov (1977a) and other his publications were an extension of these works. Among the last publications on the problem in question, the works should be noted of A. S. Silantiev (2012a, 2012b), who studied shearing SSS of concrete in beams and the effect of longitudinal reinforcement on the strength of oblique sections, Y. V. Krasnoschekov (2009), who examined the strength of oblique sections, when lateral forces and moments act, I. N. Starishko (2016), who tested the strength of beams in oblique sections with different cross section forms. Among recent foreign studies, noteworthy are works (Hosein et al., 2020; Qin et al., 2020; Naderpour et al., 2020). 


\section{MATERIALS AND METHODS}

The main experimental data were obtained when testing beams of gas-concrete with the volume weight of $600-700 \mathrm{~kg} / \mathrm{m} 3$ and and beams made of heavy-weight concrete with. The beams were loaded with two or one symmetrically located concentrated forces. Strain gauges measured changes in concrete deformities, with strain gauges with $5 \mathrm{~mm}$ base applied for gas-concrete since there was no coarse aggregate in rosettes. Strain gauges were glued on both concrete, and tensile reinforcement in certain cases. Computers had processed the results of measurements. Gas-concrete beams were 0.15-1.19\% reinforced for tensile reinforcement.

\section{RESULTS AND DISCUSSION}

As it has been stated above, one of the problems of computations by formula (1) lies in determining cleaving-shearing stresses in concrete, related to the action of shear forces. They are difficult to define due to complexity of estimating the concrete SSS. In practice, they are compared with shearing stresses, associated with the action of longitudinal forces, and, most commonly, with readily determined concrete tensile strength. E. Mersch (1927) suggested that the concrete shear value should be determined by formula $R_{s h}=\sqrt{R_{b} R_{b t}}$. The formula was further revised in various ways (mostly based on the Mohr's theory) and such its form has been used up to now. According to Stolyarov Y.V. (Stoletov, 1941) $R_{s h}=$ $1.5 \tau, \tau=2 R_{b t}$ and

$$
\tau=\frac{\sqrt{R_{b} R_{b t}}}{1.5}
$$

As per A. S. Zalesov (1989) $R_{s h}<0.5 R_{b}$. Taking into account that the maximum ratio between tensile strength and compression strength relates to low grades of concrete and for B15 $R_{b t} / R_{b}=0.10$, and if $\tau_{\max }=2.5 R_{b t}, R_{s h}<2 \tau_{\max }$. According to A. S. Silantiev (2012a) $R_{s h}=4-5 R_{b t}$ and, therefore,

$$
\tau=2 R_{b t}
$$

can be assumed, as Stolyarov Y.V. recommends. In (Morozov, 2015, 2019b) $\tau=0.185 R_{b}$ was derived for gas-concrete, what provides $\tau=1,5 R_{b t}$ for B2,5. In (141)(142) of SNiP 2.03.01-84, formation of critical inclined cracks is defined that coincides with the last stages of loading the beams, based on which in (Morozov, 2019a, 2019b) a formula of $\tau_{\max }$ was derived for a neutral axis

$$
\tau=\frac{R_{b t}}{a-{ }^{R} b t / R_{b}}
$$

where $\mathrm{a}=0.2+0.01 \mathrm{~B}$, where, according to (Morozov, 2018, 2019a) strength class $\mathrm{B}$ can be equated to the experimental values of prism strength, and computations by (141)(142) are made using the rated parameters of concrete strength, and (10) should be at least 0.5 . Table 1 presents the options for standard values of shearing stresses.

Table 1. Values of shear stresses.

\begin{tabular}{ccccccccc}
\hline $\begin{array}{c}\text { Concrete } \\
\text { class }\end{array}$ & B15 & B20 & B25 & B30 & B35 & B40 & B45 & B50 \\
\hline$\tau_{1} M P a$ & 2.75 & 3.29 & 3.72 & 4.16 & 4.11 & 4.00 & 3.90 & 3.90 \\
$\tau_{2} M P a$ & 2.32 & 3.00 & 3.57 & 4.13 & 4.69 & 5.20 & 5.65 & 6.20 \\
$\tau_{3} M P a$ & 2.20 & 2.70 & 3.10 & 3.50 & 3.90 & 4.20 & 4.50 & 4.90 \\
\hline
\end{tabular}


The table contains $\tau_{1}$ as per (10), $\tau_{2}$ as per (8), $\tau_{3}=2 R_{b t}(9)$. It is seen from the table that maximum values of shearing stresses are in line with formula (9), the values of which are refined by many researchers, $\tau_{2}$ and $\tau_{1}$ approximately correspond to each other down to B 40 . In this case, $\tau_{1}$ from B35 ceases rising, what is illogical. Hence, when calculating shear force using formula (5) $\tau_{1}$ can be assumed down to $\mathrm{B} 35, \tau_{3}$ and $\tau_{2}$ - within the entire range of concrete strength classes. Table 2 , based on experimental data of A.S. Silantiev (2012a), presents the results of computing by formula (5). Since in (Silantiev, 2012a) in most beams without compressed reinforcement according to (Morozov, 2019b), a coefficient of completeness of compression stress-block $\omega$ using the considered method is close to $\omega=$ 0.33 , we will take this value of it, to which $m=0.5$ corresponds as per ( 3 ) and $\beta=0.25$. Only in two beams No.9 and $10 \omega=0.6$, to what $\mathrm{m}=1.17$ and $\beta=0.37$ correspond. At

$$
\omega \leq 0.5 \beta=\frac{1+6 \omega}{12}
$$

and at $\omega \geq 0.5$

$$
\beta=\frac{1+2 \omega}{6}
$$

$z=\left(1-\beta \xi_{0}\right) h_{0}$, and the values of shearing stresses are as per (9) and (10). To assume more precise initial conditions, more experimental data are needed. Table 2, based on experimental data (Silantiev, 2012a), presents the results of direct determination of load-carrying capacity of beams according to the accepted initial conditions.

Table 2. Results of calculating strength of beams

\begin{tabular}{ccccccccc}
\hline Beam No. & $\mathbf{1}$ & $\mathbf{4}$ & $\mathbf{5}$ & $\mathbf{6}$ & $\mathbf{7}$ & $\mathbf{8}$ & $\mathbf{9}$ & $\mathbf{1 0}$ \\
\hline $\mathrm{Q} \mathrm{kN}$ & 23.11 & 21.5 & 48.4 & 50.69 & 31.44 & 42.66 & 74.85 & 85.00 \\
$R_{b} \mathrm{MPa}$ & 30.5 & 18.5 & 29.0 & 29.0 & 22.0 & 22.0 & 20.5 & 20.5 \\
$R_{b t} \mathrm{MPa}$ & 2.22 & 1.60 & 2.19 & 2.19 & 1.82 & 1.82 & 1.72 & 1.72 \\
$\mathrm{~b}, \mathrm{~cm}$ & 10.3 & 10.0 & 10.2 & 10.4 & 10.0 & 10.3 & 14.9 & 15.1 \\
$h_{0} \mathrm{~cm}$ & 16.0 & 16.0 & 18.0 & 18.0 & 21.4 & 22.0 & 15.0 & 14.8 \\
$a / h_{0}$ & 2.3 & 2.3 & 2.0 & 2.0 & 1.7 & 1.7 & 1.9 & 1.9 \\
$\tau_{1}(10)$ & & & & & & & & \\
$\mathrm{MPa}$ & 5.17 & 3.86 & 5.26 & 5.26 & 4.37 & 4.37 & 3.94 & 3.94 \\
$\tau_{2}(9) \mathrm{MPa}$ & 4.44 & 3.20 & 4.38 & 4.38 & 3.64 & 3.64 & 3.44 & 3.44 \\
$Q_{1} \mathrm{kN}$ & 36.4 & 25.3 & 41.8 & 43.6 & 46.8 & 49.6 & 70.7 & 78.2 \\
$Q_{2} \mathrm{kN}$ & 32.0 & 21.8 & 35.8 & 35.6 & 34.8 & 36.5 & 59.1 & 65.1 \\
\hline
\end{tabular}

In the table, $Q_{1}$ corresponds to $\tau_{1}$ and $Q_{2}-$ to $\tau_{2}$

The calculation results given in the table, demonstrate that the design values of shear force according to (4) with specified initial parameters approximately correspond to each other and experimental values of this force (by mean values $Q_{1} /_{Q}=1.04$, and $Q_{2} /_{Q}=0.85$ ). Here, preference should be given to the computation with shearing stresses by (10) with concrete strength classes down to B35. A similar approach shall also be employed to our experimental data from beams of gas-concrete (Morozov, 1985), what is presented in Table 3, where there are also the results of computing stresses in tensile reinforcement (compressed zone is not reinforced). Stresses were calculated by formulas $-\sigma_{s 1}=\frac{m \tau}{\mu} \frac{a}{h_{0}}$ (7) and

$$
\sigma_{s 2}=600 \omega\left(\sqrt{1+\frac{R_{b}}{300 \mu k}}-1\right)
$$


which was derived in (Morozov, 2018). In this case, coefficient $k=x / x_{0}$ is the ratio between the height of compressed zone, in line with the hypothesis of plane sections $-x-\frac{\varepsilon_{b}}{\varepsilon_{s}+\varepsilon_{b}} h_{0}$, and actual height of this zone, which for gas-concrete beams upon their failure across normal sections is less than one - reaches 0.9 - 1.0, and upon their failure across oblique sections is more than one (about 1.14 on an average, and, in certain cases prior to failure or probably at its onset reaches $\mathrm{K}=1.7$ ). This fact significantly complicates the estimate of the concrete SSS. Since the presented data relate to only weak and highly deformable gasconcrete, and there are no such data found for the heavy-weight concrete, in this work $\mathrm{K}=1$ is assumed.

Table 3. Calculation of shear force and stresses in reinforcement.

\begin{tabular}{cccccccc}
\hline Beam No. & BK-1 & BK-2 & B14-1 & B18-1 & B18-2 & BD-1 & BD-2 \\
\hline$R_{b} \mathrm{MPa}$ & 2.55 & 2.46 & 3.00 & 2.95 & 3.47 & 2.16 & 2.55 \\
$R_{b t} \mathrm{MPa}$ & 0.35 & 0.31 & 0.39 & 0.37 & 0.39 & 0.27 & 0.32 \\
$\mu \%$ & 0.27 & 0.10 & 0.980 & 0.733 & 0.707 & 0.767 & 0.772 \\
$\mathrm{~b}$ cm & 15.0 & 15.0 & 15.6 & 15.7 & 16.2 & 15.5 & 15.4 \\
$h_{0} \mathrm{~cm}$ & 20.0 & 20.5 & 20.7 & 20.3 & 20.5 & 20.0 & 20.0 \\
$a$ & 2.5 & 2.46 & 2.44 & 1.99 & 1.97 & 3.12 & 3.12 \\
$Q_{0} \mathrm{kN}$ & 7.9 & 7.3 & 9.5 & 9.6 & 10.8 & 6.3 & 7.4 \\
$Q_{a c t} \mathrm{kN}$ & 8.5 & 8.3 & 8.5 & 10.0 & 12.5 & 6.5 & 7.0 \\
$\sigma_{s 1} \mathrm{MPa}$ & 139.6 & 124.8 & 97.1 & 100.9 & 109.7 & 111.9 & 132.6 \\
$\sigma_{s 2} \mathrm{MPa}$ & 107.0 & 106.2 & 84.3 & 106.0 & 125.7 & 78.5 & 89.9 \\
$\sigma_{a c t} \mathrm{MPa}$ & 102.9 & 138.4 & 65.9 & 72.0 & 95.2 & 86.6 & 79.2 \\
\hline
\end{tabular}

Table 3 presents the data on the strength of gas-concrete beams in oblique cross-sections. Here, $\omega=$ 0.33, $\mathrm{m}=0.5, \tau=2 R_{b t}$ were assumed as the initial calculation parameters likewise for heavy-weight concrete beams. Shear force is calculated by formula (5). Moreover, the table presents the results of computing across the tensile zone with determination of stresses in longitudinal reinforcement using formulas (8) and (13). The last formula was derived in (Morozov, 2018) allowing for distortion of normal sections, what both makes more accurate and complicates the estimate of concrete SSS in design sections. It can be seen from the table that the design values of shear force correspond well to their actual values. Thus, mean ratio $Q_{1} /_{Q_{a c t}}=0.97, \sigma=0.09$. The ratio between mean values of reinforcement stresses and their measured values for formula (8) is 1.31 on an average at $\sigma=0.24$, and as per (13) 1.12 and 0.23 , respectively. As pointed out above, no distortion of sections was taken into account $-\kappa=1$. The above-stated suggests that the assumed initial parameters for both compressed and tensile zone can be preliminarily used to directly determine the shear force. In Y.V. Krasnoschekov (2009) estimated the experimental data of (Zalesov \& Ilyin, 1977a) according to the existing norms, and in (Morozov, 2019b) these data were supplemented by a direct calculation of shear force with the initial calculation parameters, somewhat different from those assumed in this work, and their values were greater by a third than the analogous rates for norms. Table 4 presents the results of calculation using the initial data for beams without compressive reinforcement.

Table 4. Results of direct calculation of shear force

\begin{tabular}{cccccccc}
\hline Beam No. & $\mathbf{I n ~} \mathbf{~ m}$ & $\mathbf{h}_{\mathbf{0}} \mathbf{c m}$ & $\mathbf{B} \mathrm{MPa}$ & $\mathbf{R}_{\mathbf{b}} \mathrm{MPa}$ & $\mathbf{R}_{\mathbf{b t}} \mathrm{MPa}$ & $\mathbf{Q}_{\mathbf{1}} \mathrm{kN}$ & $\mathbf{Q}_{\mathbf{2}} \mathrm{kN}$ \\
\hline 1 & 15.2 & 27.0 & 20 & 11.5 & 0.9 & 27.7 & 32.9 \\
2 & 15.4 & 25.8 & 20 & 11.5 & 0.9 & 26.8 & 31.8 \\
3 & 15.5 & 26.0 & 20 & 11.5 & 0.9 & 27.2 & 32.2 \\
6 & 15.5 & 26.7 & 28 & 16 & 1.14 & 35.4 & 42.1 \\
7 & 15.5 & 26.8 & 28 & 16 & 1.14 & 35.5 & 42.3 \\
8 & 14.5 & 26.8 & 28 & 16 & 1.14 & 33.2 & 39.7 \\
\hline
\end{tabular}




\begin{tabular}{cccccccc}
\hline 9 & 14.7 & 26.6 & 28 & 16 & 1.14 & 32.4 & 39.9 \\
14 & 14.4 & 27.3 & 42 & 23.2 & 1.42 & 41.9 & 50.7 \\
\hline
\end{tabular}

In the table: $\mathrm{Q}_{1}$ - shear force according to existing norms (Krasnoschekov, 2009), $\mathrm{Q}_{2}-$ shear force when determined directly.

It can be seen from the Table that, at the level of design resistances of concrete, the values of the shear force when determined directly by formulas (4) (5) (7) (10) (12) with $\omega=0.333, \frac{a}{h_{0}}=2, \tau=$ $2 R_{b t}, \xi_{0}=6 \frac{R_{b t}}{R_{b}}, Q_{b}=b h_{0}\left(1-0.25 \xi_{0}\right) 2 R_{b t} 0.5$ are higher by $20 \%$ than the values of the shear force, computed using the existing norms. The problems of calculating strength of oblique sections should involve a division between the forms of their failure (compression or shear). With this method, this question is addressed through detailed consideration of experimental data on the design model according to the figure, comparing $m_{2}$ with $m_{0}$ and when the first indicator is exceeded, shearing failure should be expected. Although the work of A. S. Silantiev (2012a) relates to examining concrete shearing failure in oblique sections, judging by the observed limit concrete compression deformities, some beams are likely to fail from its compression. However, the direct computation of shear force with assumed initial parameters has shown its compliance with experimental data. It suggests the potential application of direct determination of shear force for both cases of failure in oblique cross-sections. The problem lies in finding correct initial design parameters for $\omega$ and $\tau$, using experimental data. According to the assumed option in (4) $\mathrm{m} \tau=R_{b t}$.

\section{CONCLUSIONS}

The method for direct determination of shear force taken up by concrete in oblique cross-sections, is based on a stress-block of normal stresses with a cut-out, oriented towards the top of an inclined crack.

The standard formula for determining shear force (1) is supplemented with correction factor $\mathrm{m}\left(m_{2}\right.$ or $\left.m_{0}\right)$.

The direct determination of shear force is made through simultaneous solution of the equations of equilibrium in the moments in normal and oblique sections (moments of normal and lateral forces) for both compressed and tensile zone of normal section, passing through the top of an inclined crack, what, in the last case provides a way of estimating stresses in tensile reinforcement.

The design values of shear force directly determined by the assumed initial design rates $\omega$ and $\tau$, in both current and previously conducted works, corresponds to the measured values of this force in experimental beams.

Reaching maximum shearing stresses and the respective coefficient $m_{2}(2)$ near the top of an inclined crack (the $x_{2}$ ordinate) is a criterion for concrete shear failure in oblique cross-sections.

From a balance of flexural moments along the tensile zone of the design normal section, passing through the top of an inclined crack, and in oblique cross-section, a formula has been derived of stresses in tensile reinforcement (8). The stresses in tensile reinforcement computed using this formula are in compliance with its measured values in gas-concrete beams.

Deviations of design section from the hypothesis of plane sections were not accounted for in this work $\mathrm{K}=1$.

To practically determine shear force, the initial design parameters should be made more precise based on experimental data. $\omega=0.333$ and $\tau=2 R_{b t}$ can be preliminarily assumed. 
According to the assumed design data, in the conducted works the values of shear force, taken up by concrete, exceed its values, calculated according to the existing norms, by 20-30\%.

\section{REFERENCES}

Borishanskiy, M. S. (1946). Computation of unbent rods and clamps in bended reinforced concrete elements at the destruction stage. Moscow: Stroyizdat.

Gvozdev, A.cvA. (1949). Computation of load carrying capacity of structures using the limit equilibrium method. Moscow: Stroyizdat.

Kani, G. N. I. (1966). Basic Facts Concerning Shear Failure. Journal of ACI, 63(6), 675-692.

Krasnoschekov, Y. V. (2009). Strength of reinforced concrete elements in oblique sections when shear forces and moments act jointly. Bulletin of the Siberian State Automobile and State University, 3(13), 4650.

Mersch, E. (1927). Nochmals zur frage der Schubsicherung .Beton und Eisen, 7, 24

Morozov, A. N. (1985). The study of strength of structures from cinder-shale gas-concrete in oblique sections. Construction Research Institute of the ESSR, Moscow: Gosstroy.

Morozov, A. N. (1992). On new approaches to the theory of strength of gas-concrete elements in oblique sections. Construction studies. Tallinn: Estonian Construction Research Institute. pp. $10-25$.

Morozov, A. N. (2015). On some concepts of calculating strength of reinforced concrete elements in oblique sections with acting shear forces (by an example of examining gas-concrete behaviour). Problemy sovremennoy nauki e obrazovaniya (Problems of modern science and education), 4, 41-51.

Morozov, A. N. (2018). On the strength theory of reinforced concrete elements in oblique sections. Promyshlennoye e grazhdanskoye stroitelstvo, 2, 53 - 59.

Morozov, A. N. (2019a). Direct definition of cross-sectional force in sloping sections of reinforced concrete structures. Problems of modern science and education. Problemy sovremennoy nauki $e$ obrazovaniya (Problems of modern science and education), 11, 33 - 39.

Morozov,A. N. (2019b). Calculation of shear force taken up by concrete in oblique sections of reinforced concrete elements (to be discussed). Promyshlennoye e grazhdanskoye stroitelstvo (Industrial and civil construction), $12,30-34$

Naderpour, H., \& Mirrashid, M. (2020). A novel definition of damage states for structural elements in framed reinforced concrete building. Journal of Building Engineering, 32, 101479. doi: 10.1016/j.jobe.2020.101479

Qin, F., Zhang, Zh., Yin, Zh., Di, J., Xu, L., Xu, X. (2020). Use of high strength, high ductility engineered cementitious composites (ECC) to enhance the flexural performance of reinforced concrete beams. Journal of Building Engineering, 32: 101746. https://doi.org/10.1016/j.jobe.2020.101746

Said, M., Adam, M. A., Arafa, A. E., \& Moatasem, A. (2020). Improvement of punching shear strength of reinforced lightweight concrete flat slab using different strengthening techniques. Journal of Building Engineering, 32, 10749. doi: 10.1016/j.jobe.2020. 101749 
Silantiev, A. S. (2012a). Strength of bended reinforced concrete elements without clamps in oblique sections with allowance for longitudinal reinforcement parameters. MSUCE Bulletin, 2, 163-169.

Silantiev, A. S. (2012b). Experimental study of the effect of longitudinal reinforcement on resistance of bended reinforced concrete elements without shear reinforcement in oblique sections. Promyshlennoye $e$ grazhdanskoye stroitelstvo, 1, 58-61.

Starishko, I. N. (2016). Results of experimental studies of the effect of main factors on the load carrying capacity in oblique sections of bended reinforced concrete rectangular- and T-shape beams. MSUCE Bulletin, 7, 18-32.

Stoletov, Ya. V. (1941). Introduction to the theory of reinforced concrete. Moscow: Stroyizdat.

Talbot, F. (1909). Tests of Reinforced Concrete Beams: Resistance of Web Stresses. Bulletin University of Illinois Experiment Station, No. 29

Zalesov, A. S., \& Ilyin, O. F. (1977a). Resistance of reinforced concrete beams to the action of shear forces. Moscow: Stroyizdat.

Zalesov, A. S., \& Klimov, Y. A. (1989). Strength of reinforced concrete structures when shear forces act. Kishinev: Budivel'nyk.

Zalesov, A. S., Ilyin O. F. (1977b). Experience of developing a new theory of the strength of beams in the area of action of shear forces. Moscow: Stroyizdat. 